University of Wollongong

Research Online

2016

\title{
Psychological distress in carers of Aboriginal children in urban New South Wales: findings from SEARCH (phase one)
}

Anna Williamson

The Sax Institute

Catherine A. D'Este

University of Wollongong

Kathleen F. Clapham

University of Wollongong, kclapham@uow.edu.au

Sandra Eades

Baker IDI Heart and Diabetes Institute

Sally Redman

The Sax Institute, sally.redman@saxinstitute.org.au

See next page for additional authors

Follow this and additional works at: https://ro.uow.edu.au/ahsri

Research Online is the open access institutional repository for the University of Wollongong. For further information contact the UOW Library: research-pubs@uow.edu.au 


\title{
Psychological distress in carers of Aboriginal children in urban New South Wales: findings from SEARCH (phase one)
}

\author{
Abstract \\ Objective: To examine the factors associated with psychological distress in parents and carers of \\ Aboriginal children living in urban communities in New South Wales. Design: Cross-sectional survey \\ (phase one of the Study of Environment on Aboriginal Resilience and Child Health [SEARCH], November \\ 2007 - December 2011). Setting and participants: Primary care; 589 parents and carers of Aboriginal \\ children were recruited when attending one of the four Aboriginal Community Controlled Health Services \\ (ACCHSs) in urban NSW that participated in SEARCH. Main outcome measure: Kessler Psychological \\ Distress Scale (K10) scores; a score of 22 or higher was deemed to indicate high levels of psychological \\ distress. Results: High levels of psychological distress were identified in $18 \%$ of our sample. The factors \\ most strongly associated with this distress were functional limitations ( $v$ those with K10 scores under 22: \\ adjusted odds ratio [aOR], $4.2 ; 95 \% \mathrm{Cl}, 1.3-13.5)$, previous hospitalisation (aOR, 5.5; $95 \% \mathrm{Cl}, 1.5-19.4)$ or \\ other treatment for social and emotional wellbeing (aOR, 3.3; $95 \% \mathrm{Cl}, 1.3-8.4)$, low satisfaction with \\ feeling part of the community (aOR, $0.83 ; 95 \% \mathrm{Cl}, 0.70-0.98)$ and low involvement in clubs and groups \\ (aOR, 2.9; $95 \% \mathrm{Cl}, 1.2-7.3)$. Conclusions: Clinicians should note that those with functional limitations or a \\ history of treatment for mental health problems are at higher risk of psychological distress and may \\ require additional support. Increased funding that allows ACCHSs to provide mental health services, and \\ funding and promoting programs and activities that increase social connectedness should remain \\ focuses for ACCHSs and policy makers.

\section{Publication Details} \\ A. Williamson, C. A. D'Este, K. F. Clapham, S. J. Eades, S. Redman \& B. Raphael, "Psychological distress in \\ carers of Aboriginal children in urban New South Wales: findings from SEARCH (phase one)", Medical \\ Journal of Australia 2051 (2016) 27-32.

\section{Authors} \\ Anna Williamson, Catherine A. D'Este, Kathleen F. Clapham, Sandra Eades, Sally Redman, and Beverley \\ Raphael
}




\title{
Psychological distress in carers of Aboriginal children in urban New South Wales: findings from SEARCH (phase one)
}

\author{
Anna B Williamson', Catherine A D'Este ${ }^{2,3}$, Kathleen F Clapham ${ }^{3,4}$, Sandra J Eades ${ }^{1,5}$, Sally Redman', \\ Beverley Raphael ${ }^{6}$
}

The known Aboriginal children are at increased risk of mental health problems. The mental health of parents affects that of their children.

The new Psychological distress was common in parents and carers of Aboriginal children participating in SEARCH, and was associated with functional limitations, previous treatment for mental health problems, and low social connectedness.

The implications Carers with functional limitations or a history of treatment for mental health problems may require additional mental health support. Providing adequate mental health services and the funding and promoting of programs and activities that increase social connectedness should remain focuses for ACCHSs and policymakers.
$\mathrm{P}$ arents and carers play a critical role in the social and emotional wellbeing of their children. A link between parental and child mental health has been firmly established in the mainstream literature, ${ }^{1-3}$ but remains largely unstudied in Aboriginal health. Emerging evidence from phase one of the Study of Environment on Aboriginal Resilience and Child Health (SEARCH), however, indicates that children with carers who are not psychologically distressed have significantly better chances of enjoying social and emotional wellbeing than those with distressed carers (unpublished data of authors AW, $\mathrm{CD}$ and $\mathrm{KC}$ ). These findings indicate that improving the mental health of the parents and carers of the next generation of Aboriginal young people must be a priority if real gains are to be made in closing the health and wellbeing gaps between Aboriginal and non-Aboriginal people. In contrast, qualitative research indicates that Aboriginal parents often feel unable to access mental health services because they fear that their children might be removed. ${ }^{4}$

Our study examined psychological distress in the primary carers of Aboriginal children living in urban communities and attending Aboriginal Community Controlled Health Services (ACCHSs) in New South Wales. ACCHSs provide comprehensive primary health care for Aboriginal people in a culturally appropriate manner. ${ }^{5,6}$ The carers participated in phase one of SEARCH, the largest cohort study of urban Aboriginal children ever conducted. ${ }^{7}$ Specifically, we aimed to:

- determine the proportion of carers participating in the SEARCH program who meet Kessler Psychological Distress Scale (K10) criteria for high levels of psychological distress; and

\section{Abstract}

Objective: To examine the factors associated with psychological distress in parents and carers of Aboriginal children living in urban communities in New South Wales.

Design: Cross-sectional survey (phase one of the Study of Environment on Aboriginal Resilience and Child Health [SEARCH], November 2007 - December 2011).

Setting and participants: Primary care; 589 parents and carers of Aboriginal children were recruited when attending one of the four Aboriginal Community Controlled Health Services (ACCHSs) in urban NSW that participated in SEARCH.

Main outcome measure: Kessler Psychological Distress Scale (K10) scores; a score of 22 or higher was deemed to indicate high levels of psychological distress.

Results: High levels of psychological distress were identified in $18 \%$ of our sample. The factors most strongly associated with this distress were functional limitations ( $v$ those with $\mathrm{K} 10$ scores under 22: adjusted odds ratio [aOR], 4.2; 95\% Cl, 1.3-13.5), previous hospitalisation (aOR, 5.5; 95\% Cl, 1.5-19.4) or other treatment for social and emotional wellbeing (aOR, 3.3; $95 \% \mathrm{Cl}$, 1.3-8.4), low satisfaction with feeling part of the community (aOR, 0.83; 95\% Cl, 0.70-0.98) and low involvement in clubs and groups (aOR, 2.9; 95\% Cl, 1.2-7.3).

Conclusions: Clinicians should note that those with functional limitations or a history of treatment for mental health problems are at higher risk of psychological distress and may require additional support. Increased funding that allows ACCHSs to provide mental health services, and funding and promoting programs and activities that increase social connectedness should remain focuses for ACCHSs and policy makers.

- examine the associations between demographic, health and community (neighbourhood and social) factors and psychological distress.

\section{Methods}

\section{SEARCH}

The protocol for phase one of the SEARCH study was published in 2010. ${ }^{7}$ SEARCH is a partnership between researchers, ACCHSs and the Aboriginal Health and Medical Research Council. The overall aim is to describe and investigate factors associated with health and illness in urban Aboriginal children aged 0-17 years who attend participating ACCHSs, as well as in their parents and caregivers. 
1 Characteristics of carers of Aboriginal children participating in phase one of SEARCH

\begin{tabular}{|c|c|c|c|c|}
\hline \multirow[b]{2}{*}{ Variable } & \multirow[b]{2}{*}{ Total* } & \multicolumn{2}{|c|}{ Kessler Psychological Distress Scale score } & \multirow[b]{2}{*}{$P^{\dagger}$} \\
\hline & & $<22$ (Low to moderate distress)* & $\geq 22$ (High to very high distress)* & \\
\hline Number & 589 & $481(81.7 \%)$ & $108(18.3 \%)$ & \\
\hline Age (years), mean (standard deviation) & $34.3(9.9)$ & $34.4(10.3)$ & $33.6(8.4)$ & 0.46 \\
\hline \multicolumn{2}{|l|}{ Aboriginal and/or Torres Strait Islander } & & & 0.05 \\
\hline Yes & $457(78 \%)$ & $114(88 \%)$ & $16(12 \%)$ & \\
\hline No & $130(22 \%)$ & $365(80 \%)$ & $92(20 \%)$ & \\
\hline \multicolumn{2}{|l|}{ Employment status } & & & 0.02 \\
\hline Employed/studying & $200(34 \%)$ & $174(87 \%)$ & $26(13 \%)$ & \\
\hline Unemployed/retired/unable to work & $71(12 \%)$ & $52(73 \%)$ & $19(27 \%)$ & \\
\hline Home duties & $312(54 \%)$ & $252(81 \%)$ & $60(19 \%)$ & \\
\hline \multicolumn{2}{|l|}{ Qualifications } & & & 0.62 \\
\hline None & 289 (51\%) & $234(81 \%)$ & $55(19 \%)$ & \\
\hline Trade certificate/diploma/other & $236(42 \%)$ & $191(81 \%)$ & $45(19 \%)$ & \\
\hline Bachelor or postgraduate degree & $41(7.2 \%)$ & $36(88 \%)$ & $5(12 \%)$ & \\
\hline \multicolumn{2}{|c|}{$\begin{array}{l}\text { Were you taken away from your natural family by a } \\
\text { mission, the government or welfare? }\end{array}$} & & & 0.15 \\
\hline Yes & $28(4.9 \%)$ & $25(89 \%)$ & $3(11 \%)$ & \\
\hline No & $530(93 \%)$ & $427(81 \%)$ & $103(19 \%)$ & \\
\hline \multicolumn{2}{|c|}{$\begin{array}{l}\text { Were either of your parents or other relatives taken away } \\
\text { from their natural family by a mission, the government or } \\
\text { welfare? }\end{array}$} & & & 0.008 \\
\hline Yes, parent & $70(12 \%)$ & $48(69 \%)$ & $22(31 \%)$ & \\
\hline Yes, other relative & $94(16 \%)$ & $73(78 \%)$ & $21(22 \%)$ & \\
\hline No & $332(54 \%)$ & $284(86 \%)$ & $48(14 \%)$ & \\
\hline
\end{tabular}

Families in the target population were eligible to participate in phase one if the parent or caregiver was over 16 years of age and willing to provide contact information for follow-up interviews. SEARCH is conducted in partnership with four ACCHSs in NSW: Mount Druitt (Aboriginal Medical Service Western Sydney); Campbelltown (Tharawal Aboriginal Corporation); Wagga Wagga (Riverina Medical and Dental Aboriginal Corporation) and Newcastle (Awabakal Aboriginal Cooperative).

Families meeting inclusion criteria were invited by an Aboriginal research assistant to participate in SEARCH when they presented to a participating ACCHS. Participants in SEARCH will be followed up 5 years after recruitment; this article reports on the baseline cross-sectional data collected during phase one (November 2007 - December 2011).

\section{Measures}

As part of the SEARCH phase one survey, the parents or carers of participating children completed a comprehensive survey about their children's health and wellbeing. Carers also completed a questionnaire about themselves that collected data on a range of demographic, social, lifestyle and health-related factors, including health service use, community and family resilience, and quality and safety of housing. The questionnaire was based on the Western Australian Aboriginal Child Health Survey ${ }^{8}$ and the New South Wales Child Health Survey. ${ }^{9}$
The K10 scale was used to measure non-specific psychological distress in carers. ${ }^{10}$ High K10 scores are strongly associated with current World Health Organization Composite International Diagnostic Interview (CIDI) diagnoses of anxiety and affective disorders, and are also associated with the presence of any mental disorder. ${ }^{11}$ A score of 22 or higher was deemed to indicate high levels of psychological distress, consistent with previous investigations. ${ }^{12}$ The K10 has been found to be a valid measure of distress in Aboriginal adults in NSW. ${ }^{13}$

\section{Statistical methods}

All parents or carers for whom a K10 score could be calculated (9 of 10 items must be completed for a valid score to be generated) were included in this study. Characteristics of the sample are presented as means and standard deviations or as frequencies and percentages. The proportion of carers with high psychological distress, and $95 \%$ confidence intervals (CIs), were calculated. Each variable of interest was initially included in a separate logistic regression model that controlled for age, sex and ACCHS. All variables for which $P<0.20$ or which were considered to be clinically important (such as age and sex) were included in the multiple regression models. A separate model was performed for each of the three domains of explanatory variables: demographic, health, and community factors. A final model was then generated that included all significant variables from the three models. 
2 Association of high psychological distress in carers of Aboriginal children in the SEARCH study with demographic factors

Adjusted odds ratio ( $95 \% \mathrm{Cl})$, after adjusting for:

\begin{tabular}{|c|c|c|c|c|c|}
\hline \multirow[b]{2}{*}{ Variable } & \multirow[b]{2}{*}{ Total number } & \multirow[b]{2}{*}{ Number (\%) } & \multicolumn{3}{|c|}{ Adjusted odds ratio ( $95 \% \mathrm{Cl}$ ), after adjusting for: } \\
\hline & & & Age, sex, ACCHS & $\begin{array}{l}\text { Age, sex, ACCHS, significant } \\
\text { demographic factors* }\end{array}$ & $\begin{array}{l}\text { Age, sex, ACCHS, all } \\
\text { significant factors }\end{array}$ \\
\hline \multicolumn{6}{|l|}{ Sex } \\
\hline Men & 55 & $7(13 \%)$ & 1.0 & 1.0 & 1.0 \\
\hline Women & 534 & $101(19 \%)$ & $1.5(0.65-3.3)$ & $1.3(0.57-3.0)$ & $1.0(0.23-4.6)$ \\
\hline \multicolumn{6}{|l|}{ Aboriginal and/or Torres Strait Islander } \\
\hline No & 130 & $16(12 \%)$ & 1.0 & 1.0 & \\
\hline Yes & 457 & $92(20 \%)$ & $1.7(0.98-3.0)$ & $1.2(0.68-2.2)$ & \\
\hline \multicolumn{6}{|l|}{ Employment status } \\
\hline Employed/studying & 200 & $26(13 \%)$ & 1.0 & 1.0 & 1.0 \\
\hline Unemployed/retired/unable to work & 71 & $19(27 \%)$ & $2.5(1.3-4.9)$ & $2.4(1.2-4.8)$ & $0.86(0.24-3.1)$ \\
\hline Home duties & 312 & $60(19 \%)$ & $1.5(0.93-2.5)$ & $1.6(0.98-2.7)$ & $0.9(0.35-2.3)$ \\
\hline \multicolumn{6}{|l|}{ Qualifications } \\
\hline None & 289 & $55(19 \%)$ & 1.0 & & \\
\hline Trade certificate/diploma & 236 & $45(19 \%)$ & $1.0(0.66-1.6)$ & & \\
\hline Bachelor or postgraduate & 41 & $5(12 \%)$ & $0.62(0.24-1.6)$ & & \\
\hline \multicolumn{6}{|l|}{ Housing tenure } \\
\hline Owned by someone in household & 125 & $16(13 \%)$ & 1.0 & & \\
\hline Social housing & 139 & $28(20 \%)$ & $1.7(0.85-3.3)$ & & \\
\hline Rental & 304 & $61(20 \%)$ & $1.6(0.90-3.0)$ & & \\
\hline \multicolumn{6}{|l|}{ Number of children cared for } \\
\hline$<4$ & 420 & 78 (19\%) & 1.0 & & \\
\hline$\geq 4$ & 48 & $12(25 \%)$ & $1.56(0.78-3.2)$ & & \\
\hline \multicolumn{6}{|l|}{ Carer removed from natural family } \\
\hline No, refused, or don't know & 540 & $105(19 \%)$ & 1.0 & & \\
\hline Yes & 28 & $3(11 \%)$ & $0.60(0.16-1.9)$ & & \\
\hline \multicolumn{6}{|c|}{ Carer's parents or other relatives removed from their natural family? } \\
\hline No, refused, or don't know & 399 & $64(16 \%)$ & 1.0 & 1.0 & \\
\hline Yes, other relative & 94 & $21(22 \%)$ & $1.5(0.89-2.7)$ & $1.5(0.86-2.7)$ & \\
\hline Yes, parent & 70 & $22(31 \%)$ & $2.4(1.4-4.2)$ & $2.3(1.3-4.2)$ & \\
\hline
\end{tabular}

ACCHS = Aboriginal Community Controlled Health Service. * Factors that were identified as significant (bold) in the previous column. $\dagger$ Factors that were identified as significant (bold) in the previous column in Boxes 2-4.

Univariate analyses evaluated all available cases, and multivariable modelling used complete case analysis. We assessed the sensitivity of results to imputing missing data by applying the chained regressions method of multiple imputation to generate five imputed data sets. Missing values were predicted using an iterative series of appropriate regression models (logistic or multinomial), conditional with respect to the observed values of the outcome variable, independent variables used in regression modelling, and additional measured variables. This method is appropriate for arbitrary patterns of missing data, but assumes that the data are missing at random. Modelling was performed using the pooled multiple imputation dataset, including the independent variables selected from the complete case analysis (final model). Coefficients and standard errors for the variability between imputations were combined using the method of Rubin. $^{14}$

Post hoc power calculations indicated that the overall sample size of 637 carers provided $80 \%$ power $(\alpha=0.05,2$-tailed) to detect differences of $11 \%$ in categories of study factors predictive of a high
K10 score (with an outcome prevalence of at least 70\% in the reference category). All analyses were performed in SAS 9.4 (SAS Institute) and Stata 13 (StataCorp).

\section{Ethics approval}

The study was approved by the relevant ethics committees of the Aboriginal Health and Medical Research Council of New South Wales (reference 586/06) and the University of Sydney (reference, 12-2003/9429).

\section{Results}

A total of 637 parents and carers participated in phase one of SEARCH, of whom 589 provided sufficient data for a complete K10 score and were therefore included in our study. There were no significant differences between the demographic details of participants for whom a K10 score was or was not recorded (data not shown). 
3 Association of high psychological distress in carers of Aboriginal children in the SEARCH study with health factors

Adjusted odds ratio $(95 \% \mathrm{Cl})$, after adjusting for:

\begin{tabular}{|c|c|c|c|c|c|}
\hline \multirow{2}{*}{\multicolumn{3}{|c|}{ Total number Number (\%) }} & \\
\hline & & & $\begin{array}{l}\text { Age, sex, } \\
\text { ACCHS }\end{array}$ & $\begin{array}{c}\text { Age, sex, ACCHS, } \\
\text { significant health factors* }\end{array}$ & $\begin{array}{l}\text { Age, sex, ACCHS, all } \\
\text { significant factors }{ }^{\dagger}\end{array}$ \\
\hline \multicolumn{6}{|c|}{$\begin{array}{l}\text { Has a medical condition that will last at } \\
\text { least } 6 \text { months }\end{array}$} \\
\hline Yes & 201 & $59(29 \%)$ & $3.1(2.0-4.8)$ & $1.3(0.70-2.3)$ & $0.71(0.27-1.9)$ \\
\hline \multicolumn{6}{|c|}{ Functional limitations } \\
\hline Yes & 93 & 39 (42\%) & $5.3(3.12-9.0)$ & $3.2(1.6-6.3)$ & $4.2(1.3-13.5)$ \\
\hline \multicolumn{6}{|c|}{ Number of days' exercise per week } \\
\hline None & 112 & $28(25 \%)$ & 1.0 & 1.0 & 1.0 \\
\hline $1-3$ days & 220 & $36(16 \%)$ & $0.58(0.33-1.0)$ & $0.82(0.41-1.6)$ & $1.2(0.36-4.2)$ \\
\hline 4-7 days & 236 & $41(17 \%)$ & $0.62(0.36-1.01)$ & $0.94(0.48-1.9)$ & $2.1(0.65-6.8)$ \\
\hline \multicolumn{6}{|c|}{$\begin{array}{l}\text { Previous treatment for social and } \\
\text { emotional wellbeing }\end{array}$} \\
\hline No & 356 & $36(10 \%)$ & 1.0 & 1.0 & 1.0 \\
\hline Yes & 200 & $69(35 \%)$ & $4.7(3.0-7.4)$ & $2.6(1.5-4.5)$ & $3.3(1.3-8.4)$ \\
\hline \multicolumn{6}{|c|}{$\begin{array}{l}\text { Previous hospitalisation for social and } \\
\text { emotional wellbeing }\end{array}$} \\
\hline No & 518 & 84 (16\%) & 1.0 & 1.0 & 1.0 \\
\hline Yes & 43 & $21(49 \%)$ & $4.7(2.45-9.0)$ & $2.2(1.0-5.0)$ & $5.5(1.5-19.4)$ \\
\hline
\end{tabular}

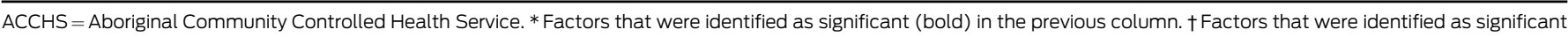
(bold) in the previous column in Boxes 2-4.

Most participating carers were female (93\%); their mean age was 34 years (Box 1). Most (78\%) identified as being Aboriginal and/or Torres Strait Islander. The majority reported home duties as their primary occupation (54\%); unemployment was uncommon $(12 \%)$. Employment status was significantly associated with the prevalence of high psychological distress (employed or studying, 13\%; home duties, 19\%; unemployed, $27 \%$; $P=0.02)$. About half of all carers $(49 \%)$ had a secondary or tertiary qualification. One in 20 carers had been removed from their natural family by a mission, the government, or a welfare agency, and $28 \%$ reported that their parents or other relatives had experienced such removal. The previous removal of carers' parents or relatives was associated with high current psychological distress (parent removed, 31\%; other relative removed, 22\%; no family history of forced removal, $14 \%$; $P<0.01)$.

Of the 589 participants with a calculated K10 score, $481(82 \%)$ had values under 22, and 108 (18\%) had high scores. The mean K10 score was 16.7 (range, 10-47; standard deviation, 7.5).

\section{Socio-demographic variables associated with high psychological distress}

In the final model, after adjusting for all important demographic, health and community factors, no socio-demographic variables retained a significant association with the level of psychological distress (Box 2).

\section{Mental and physical health factors associated with psychological distress}

In the fully adjusted model, several mental and physical health factors were significantly associated with higher odds of high psychological distress (Box 3). Forty-two per cent of those who reported experiencing a functional limitation (limited in any way in normal daily activities by a medical or health problem) were highly distressed. The odds of being psychologically distressed was more than four times higher for this group than for those without a functional limitation (adjusted odds ratio [aOR], 4.2; 95\% CI, 1.3-13.5). Previous treatment $(\mathrm{aOR}, 3.3 ; 95 \% \mathrm{CI}, 1.3-8.4)$ or hospitalisation for mental health problems (aOR, 5.5; 95\% CI, 1.5-19.4) were also significantly associated with currently high levels of psychological distress. The prevalence of distress in those who had been hospitalised for mental health problems was particularly high (49\%).

\section{Neighbourhood and community factors associated with psychological distress}

In the fully adjusted model, the odds of high psychological distress were lower for those who were more satisfied with their feeling part of their community (aOR for one unit increase in scale, 0.83; 95\% CI, 0.70-0.98) (Box 4). For those who reported infrequent involvement in clubs and groups, the odds of high psychological distress were almost three times as high as for those who engaged with such groups at least once a month (aOR, 2.9; 95\% CI, 1.2-7.3). 
4 Association of high psychological distress in carers of Aboriginal children in the SEARCH study with neighbourhood and community factors

Adjusted odds ratio $(95 \% \mathrm{Cl})$, after adjusting for:

\begin{tabular}{|c|c|c|c|c|c|}
\hline \multirow[b]{2}{*}{ Variable } & \multirow[b]{2}{*}{ Total number } & \multirow[b]{2}{*}{ Number (\%) } & \multicolumn{3}{|c|}{ Adjusted odds ratio ( $95 \% \mathrm{Cl})$, after adjusting for: } \\
\hline & & & Age, sex, ACCHS & $\begin{array}{l}\text { Age, sex, ACCHS, significant } \\
\text { community factors* }\end{array}$ & $\begin{array}{l}\text { Age, sex, ACCHS, all } \\
\text { significant factors }{ }^{\dagger}\end{array}$ \\
\hline \multicolumn{6}{|c|}{ I feel I belong in this neighbourhood } \\
\hline Agree & 360 & $50(14 \%)$ & 1.0 & 1.0 & 1.0 \\
\hline Disagree & 92 & $30(33 \%)$ & $3.0(1.8-5.1)$ & $2.7(0.91-8.2)$ & $2.5(0.59-10.3)$ \\
\hline \multicolumn{6}{|c|}{ Neighbourhood has a strong sense of community } \\
\hline Agree & 289 & $47(16 \%)$ & 1.0 & & \\
\hline Disagree & 121 & $26(21 \%)$ & $1.4(0.81-2.4)$ & & \\
\hline \multicolumn{6}{|c|}{ People in neighbourhood very willing to help others } \\
\hline Agree & 273 & $39(14 \%)$ & 1.0 & 1.0 & 1.0 \\
\hline Disagree & 140 & $36(26 \%)$ & $2.0(1.2-3.4)$ & $0.46(0.15-1.4)$ & $0.40(0.1-1.6)$ \\
\hline \multicolumn{6}{|c|}{ Crime is a problem in neighbourhood } \\
\hline No & 180 & $18(10 \%)$ & 1.0 & 1.0 & 1.0 \\
\hline Yes & 378 & $83(22 \%)$ & $2.5(1.5-4.23)$ & $2.0(0.85-4.5)$ & $1.3(0.49-3.6)$ \\
\hline \multicolumn{6}{|c|}{ Participated in groups/clubs (past year) } \\
\hline Monthly or more & 263 & $33(13 \%)$ & 1.0 & 1.0 & 1.0 \\
\hline Occasionally or never & 301 & $70(23 \%)$ & $2.1(1.3-3.2)$ & $2.4(1.2-5.0)$ & $2.9(1.2-7.3)$ \\
\hline \multicolumn{6}{|c|}{ Participated in parents groups/groups related to child (past year) } \\
\hline Monthly or more & 143 & $20(14 \%)$ & 1.0 & 1.0 & 1.0 \\
\hline Occasionally or never & 410 & $83(20 \%)$ & $1.5(0.90-2.6)$ & $1.8(0.8-4.4)$ & $2.5(0.89-7.3)$ \\
\hline $\begin{array}{l}\text { Satisfaction with feeling } \\
\text { community, }{ }^{\ddagger} \text { median (ra }\end{array}$ & $\begin{array}{l}\text { rt of } \\
\text { of responses) }\end{array}$ & $5(1-10)$ & $0.8(0.71-0.85)$ & $0.82(0.71-0.93)$ & $0.83(0.70-0.98)$ \\
\hline
\end{tabular}

\section{Discussion}

Psychological distress in the carers of Aboriginal children and adolescents who participated in phase one of SEARCH was fairly common: a high or very high level of distress was measured in about $18 \%$ of carers. SEARCH may not provide a representative sample of all carers of Aboriginal children; the proportion in our study is substantially higher than the $2.6 \%$ of mothers and $1.3 \%$ of fathers with high K10 scores in the Longitudinal Study of Australian Children, ${ }^{2}$ but substantially lower than the $30 \%$ of Aboriginal adults participating in the 2012-2013 Aboriginal and Torres Strait Islander Health Survey. ${ }^{15}$ While demographic factors are commonly linked with psychological distress, ${ }^{16,17}$ they were not significant in our study after taking the impact of health and community factors into account. The factors significantly related to high psychological distress in SEARCH carers were functional limitations, ${ }^{18,19}$ previous hospitalisation or other treatment for social and emotional wellbeing, lower satisfaction with feeling part of the community, and lower involvement in clubs and groups.

Functional limitation was associated with psychological distress, and this is consistent with a growing body of evidence which suggests that disability, rather than having a particular illness per se, has the greatest impact on mental health. ${ }^{18}$ The effect of functional limitations may be particularly distressing for parents and carers because of the inherently physical nature of parenting. Some researchers have called for depression to be routinely assessed in those with functional limitations, ${ }^{20}$ and our findings suggest that clinicians should be mindful of the elevated risk of distress in such people.
The very high prevalence of current distress in those who had previously been hospitalised or received treatment for mental health problems underscores the importance of the continuity of mental health care. Our data are concerning, as previous research has highlighted incompatibilities between mainstream mental health services and the needs of Aboriginal people ${ }^{21,22}$ and identified ACCHSs as the only places where many Aboriginal parents feel they can safely access mental health care. ${ }^{4}$ Despite these findings, $87 \%$ of ACCHSs are not funded to provide mental health care services. ${ }^{23}$ As the mental health of children improves when their parents undergo treatment for their own mental health problems, ${ }^{20}$ it is likely that providing adequate care for the parents of Aboriginal children will have far-reaching benefits.

Lack of social connectedness was strongly associated with psychological distress in SEARCH carers. Those who reported low levels of satisfaction with their feelings of belonging to their community and those who reported infrequent participation in clubs and groups were significantly more likely to meet criteria for high psychological distress. These findings are consistent with the prominent role assigned to "connection to community" in the concept of social and emotional wellbeing from an Aboriginal and Torres Strait Islander perspective described by Gee and colleagues, in which the self is seen as being grounded in the family and community. ${ }^{24}$ It also accords with observations from the National Empowerment Project, which found that many of the strategies nominated by participating Aboriginal communities as improving social and emotional wellbeing were focused on increasing the connectedness of individuals, families and communities. ${ }^{25}$ The interplay between participation and feelings of belonging has been 
explored in earlier research which suggested that Aboriginal people who participate in Aboriginal organisations and clubs find this a highly effective means of fostering a sense of belonging in the community. ${ }^{26}$ One of the many roles ACCHSs play in maintaining the social and emotional wellbeing of the parents of Aboriginal children is their providing a place where Aboriginal people can come together.

This article was designed to provide an overview of the associations between a range of demographic, physical and family factors and high levels of psychological distress in the carers of Aboriginal children in urban NSW. The following caveats should be noted. The data are cross-sectional, so that we can report associations, but are unable to infer the reasons for the relationships found. Phase two SEARCH data are currently being collected and will allow us to explore how mental health of carers changes over time, as well as predictors of improvement or worsening. The data we have presented pertain to Aboriginal families recruited through four ACCHSs in urban NSW, and may not be generalisable to parents and carers of Aboriginal children living in other parts of Australia.
Our article highlights some key areas for action in improving the social and emotional wellbeing of the parents and carers of Aboriginal children. Specifically, clinicians should note that those with functional limitations or a history of treatment for mental health problems are at higher risk for psychological distress and may require additional support. Increased funding that allows ACCHSs to provide mental health services, together with funding and promoting programs and activities that increase social connectedness, should remain focuses for ACCHSs and policy makers.

Acknowledgements: We thank the study participants, their communities and the staff at participating Aboriginal Community Controlled Health Organisations. SEARCH is funded by the Australian National Health and Medical Research Council (grant numbers 358457, APP1035378, APP1023998), an Australian Primary Health Care Research Institute Centre for Research Excellence grant, the Rio Tinto Aboriginal Foundation, and the Centre for Aboriginal Health (in the NSW Department of Health). Anna Williamson holds an NHMRC Public Health (Australia) Training Fellowship (510 391).

\section{Competing interests: No relevant disclosures.}

Received 1 Feb 2016, accepted 16 May 2016.

(c) 2016 AMPCo Pty Ltd. Produced with Elsevier B.V. All rights reserved.
1 Center on the Developing Child (Harvard University). Maternal depression can undermine the development of young children (Working Paper No. 8). National Scientific Council on the Developing Child; Harvard University, National Forum on Early Childhood Policy and Programs, 2009. http://developingchild.harvard. edu/wp-content/uploads/2009/05/MaternalDepression-Can-Undermine-Development.pdf (accessed Apr 2016).

2 Fletcher RJ, Feeman E, Garfield C, et al. The effects of early paternal depression on children's development. Med J Aust 2011; 195: 685-689. https://www.mja.com. au/journal/2011/195/11/effects-early-paternaldepression-children-s-development

3 Goldfeld S, Kvalsvig A, Incledon E, et al. Predictors of mental health competence in a population cohort of Australian children. J Epidemiol Community Health 2014; 68: 431-437.

4 Williamson A, Raphael B, Redman S, et al. Emerging themes in Aboriginal child and adolescent mental health: findings from a qualitative study in Sydney, New South Wales. Med J Aust 2010; 192: 603-605. https:// www.mja.com.au/journal/2010/192/10/emergingthemes-aboriginal-child-and-adolescent-mentalhealth-findings

5 Baba JT, Brolan CE, Hill PS. Aboriginal medical services cure more than illness: a qualitative study of how Indigenous services address the health impacts of discrimination in Brisbane communities. Int J Equity Health 2014; 13: 56.

6 Panaretto KS, Wenitong M, Button S, et al. Aboriginal community controlled health services: leading the way in primary care. Med J Aust 2014; 200: 649-652. https:// www.mja.com.au/journal/2014/200/11/aboriginalcommunity-controlled-health-services-leading-wayprimary-care

7 Study of Environment on Aboriginal Resilience and Child Health Investigators. The Study of Environment on Aboriginal Resilience and Child Health (SEARCH): study protocol. BMC Public Health 2010; 10: 287.

8 Zubrick S, Silburn SR, Lawrence DM, et al. The Western Australian Aboriginal Child Health Survey: the social and emotional wellbeing of aboriginal children and young people. Perth: Curtin University of Technology, Telethon Institute for Child Health Research, 2005.

9 Centre for Epidemiology and Research. 2005-2006 Report on child health, from the New South Wales Population Health Survey. Sydney: NSW Department of Health, 2008. http://www.health.nsw.gov.au/surveys/ child/Publications/child-health-survey-05-06.pdf (accessed Apr 2016).

10 Kessler RC, Andrews G, Colpe LJ, et al. Short screening scales to monitor population prevalences and trends in nonspecific psychological distress. Psychol Med 2002; 32: 959-976.

11 Andrews G, Slade T. Interpreting scores on the Kessler Psychological Distress Scale (K10). A N Z J Public Health 2001; 25: 494-497.

12 Australian Bureau of Statistics. 4817.0.55.001. Use of the Kessler Psychological Distress Scale in ABS health surveys, Australia, 2001 [information paper]. May 2003. http://www.abs.gov.au/ausstats/abs@.nsf/ papersbyReleaseDate/4D5BD324FE8B415FCA2579D 500161057 (accessed Apr 2016)

13 McNamara BJ, Gubhaju L, Banks E, et al. Measuring psychological distress in older Aboriginal and Torres Strait Islanders Australians: a comparison of the K-10 and K-5. A N Z J Public Health 2014; 38: 567-573.

14 Rubin D. Multiple imputation for nonresponse in surveys. New York: John Wiley \& Sons, 1987.

15 Australian Bureau of Statistics. 4727.0.55.001. Australian Aboriginal and Torres Strait Islander Health Survey: first results, Australia, 2012-13. Psychological distress. Nov 2013. http://www.abs.gov.au/ausstats/abs@.nsf/ Lookup/9F3C9BDEE98B3C5FICA257C2F00145721? opendocument (accessed Apr 2016).

16 Skapinakis P, Weich S, Lewis G, et al. Socio-economic position and common mental disorders: longitudinal study in the general population in the UK. Br J Psychiatry 2006; 189: 109-117.

17 Taylor R, Page A, Morrell S, et al. Socio-economic differentials in mental disorders and suicide attempts in Australia. Br J Psychiatry 2004; 185: 486-493.

18 Byles JE, Robinson I, Banks E, et al. Psychological distress and comorbid physical conditions: disease or disability? Depress Anxiety 2013; 31: 524-532.
19 Banks E, Byles JE, Gibson RE, et al. Is psychological distress in people living with cancer related to the fact of diagnosis, current treatment or level of disability? Findings from a large Australian study. Med I Aust 2010; 93(5 Suppl): S62. https://www.mja.com.au/journal/201 0/193/5/psychological-distress-people-living-cancerrelated-fact-diagnosis-current

20 Holden L, Scuffham P, Hilton M, et al. Psychological distress is associated with a range of high-priority health conditions affecting working Australians. Aust N Z J Public Health 2010; 34: 304-310.

21 Vicary D, Bishop B. Western psychotherapeutic practice: engaging Aboriginal people in culturally appropriate and respectful ways. Aust Psychol 2005; 40: 8-19.

22 Westerman TJ. Engagement of Indigenous clients in mental health services: what role do cultural differences play? Australian e-Journal for the Advancement of Mental Health 2004; 3: 88-94.

23 Kelly K, Dudgeon P, Gee G, et al. Living on the edge: social and emotional wellbeing and risk and protective factors for serious psychological distress among Aboriginal and Torres Strait Islander people (Discussion Paper No. 10). Darwin: Cooperative Research Centre for Aboriginal Health, 2009. http://www. indigenouspsychology.com.au/Assets/Files/AlPA-Livingon-the-Edge-web.pdf (accessed Apr 2016).

24 Gee G, Dudgeon P, Schultz C, et al. Aboriginal and Torres Strait Islander social and emotional wellbeing and mental health. In: Dudgeon P, Milroy H, Walker R, editors. Working together: Aboriginal and Torres Strait Islander mental health and wellbeing principles and practice. 2nd edition. Canberra: Australian Government Department of Health and Ageing, Telethon Institute for Child Health Research/Kulunga Research Network, 2014; pp. 55-68.

25 Cox A, Dudgeon P, Holland C, et al. Using participatory action research to prevent suicide in Aboriginal and Torres Strait Islander communities. Aust J Prim Health 2014; 20: 345-349.

26 Browne-Yung K, Ziersch A, Baum F, et al. Aboriginal Australians' experience of social capital and its relevance to health and wellbeing in urban settings. Soc Sci Med 2013; 97: 20-28. 